\title{
Potential Impact of Climate Change Trends on Wheat Production and Mitigation Strategies in Afghanistan
}

\author{
Rajiv Sharma ${ }^{1}$, Kai Sonder ${ }^{2} \&$ G. Sika ${ }^{3}$ \\ ${ }^{1}$ International Maize \& Wheat Improvement Centre (CIMMYT), Kabul, Afghanistan \\ ${ }^{2}$ International Maize \& Wheat Improvement Centre (CIMMYT), Mexico \\ ${ }^{3}$ International Maize \& Wheat Improvement Centre (CIMMYT), Nairobi, Kenya \\ Correspondence: Rajiv Sharma, CIMMYT-Afghanistan, \#157, Karte Parwan, Baharistan, Kabul, Afghanistan. \\ E-mail: rk.sharma@egiar.org
}

Received: December 24, 2014 Accepted: January 25, 2015 Online Published: March 15, 2015

doi:10.5539/jas.v7n4p40 URL: http://dx.doi.org/10.5539/jas.v7n4p40

\begin{abstract}
Climate change is here and continues unabated. It is expected to affect different biological processes differently. Afghanistan has a varied climate profile and depends heavily on wheat, the staple food of its 30 million people. The irrigated wheat occupying about 1.35 million hectare and contributes major chunk of wheat to national granaries compared to rainfed wheat which is more opportunistic with an unpredictable and uncertain share in national harvest. Previous decades have already seen a reduction of up to $100 \mathrm{~mm}$ wheat season rainfall and more reductions are estimated by 2050. Also, wheat which is a cool season crop and is also estimated to face higher temperatures by up to 5 degree Celsius across several provinces in the country. The study predicts variable impact of the estimated changes on the productivity of irrigated and rainfed wheat in Afghanistan.
\end{abstract}

Keywords: wheat, Afghanistan, climate change, production, temperature, rainfall

\section{Introduction}

Climate is defined as a change in the average pattern of temperature, humidity, precipitation and other meteorological events in any given area over an extended period of time - typically decades or longer. Climate change may be due to natural internal processes or external forces such as modulations of the solar cycles, volcanic eruptions, and persistent changes caused by human activity in the composition of the atmosphere or in land use (IPCC, 2014).

Temperature has a profound impact on soil-plant-water relationships in agriculture, influencing the rate of photosynthesis, respiration and plant growth. For wheat farmers, it is the main determinant of the potential health of crops and plays a major role in decision-making about which wheat variety to plant and when, harvest times and yield potential.

\section{Agriculture in Afghanistan}

The importance of agriculture to Afghanistan's economy cannot be over emphasized. The sector employs 60 percent of the working population and in 2013 contributed more than 20 percent to the country's overall gross domestic product, which was valued at \$20.7, billion according to the World Bank (World Bank, 2013). Statistics from the U.N. World Food Programme show that 7.6 million of its total 30.5 million people (WFP, 2014) are food insecure and 14 percent are considered to be borderline food-insecure.

However, Afghanistan, which has been embroiled in conflict for most of the past over three decades, has the potential to expand self-sufficiency and combat food insecurity notably by tackling the sector's low productivity. Exploiting this growth potential requires improving the sub-optimal productivity plaguing Afghan agriculture and further promoting the entrepreneurial capacity of semi-commercial farmers. To achieve increased production in agriculture to make a significant impact on rural areas, agriculture production needs to grow at a steady average rate of at least 5 percent per annum over the next decade. Therefore, improving production and farm income is vital to strengthening the contribution of the agriculture sector to aid in achieving economic growth and poverty reduction in Afghanistan. 


\section{Food Security}

Afghanistan ranks among the top wheat consuming countries of the world. The wheat grain is the basic food staple in the country accounting for about 80 percent of the 3.2 million hectares of land under cereals' production in the country (MAIL, 2012). It also contributes a proportionate amount to overall cereal production. Food production capacity affects its availability in remote areas and is the basis for income generation for farmers in these areas. Afghanistan's wheat production levels have varied widely over the years, and although it came close to self-sufficiency by producing 96.6 percent of wheat consumed in 2009 due to exceptionally good weather, it has never been self-sufficient in wheat. In 2004, during a particularly bad year, Afghanistan produced only 53 percent of wheat consumed in the country (MAIL, 2009).

Out of 30.5 million, almost 11 million Afghans (36 percent) live below the national poverty line (World Bank, 2013), unable to meet basic needs and dietary requirements. Food insecurity is found also in urban areas, accompanied by malnutrition. Afghanistan was more severely affected by the food price crisis of 2007-2008 than other countries due to its high level of poverty. Overall, 27.7 percent of people face a crisis situation as far as food security is concerned (IPC, 2013). Wheat is synonymous with food security as it is the staple food crop supplying about 60 percent of caloric intake to an average Afghan with an average annual per capita consumption of about 200 Kilograms (440 pounds) (Persaud, 2012).

\section{Boosting Yields}

The concerted integrated efforts of research and development agencies have resulted in the positive production and productivity growth of this commodity (Figure 1). Afghanistan's wheat production trend is highly erratic, ranging from a high of more than 5 million metric tonnes in 2009 and 2012 to a low of 2.8 in 2008 and 3.3 in 2011 (MAIL, 2012). However, Afghanistan's population has increased by 10 million over the past decade (FAO, 2013). Afghanistan is reliant on such neighboring countries as Pakistan, Uzbekistan and Iran to meet its wheat needs. The Ministry of Agriculture, Irrigation and Livestock (MAIL) has estimated that Afghanistan would need to produce about 7 million metric tons of wheat by 2022 (Waziri et al., 2013) to achieve self-sufficiency. The prospects of achieving 2 million tonnes jump in wheat production looks bleak given that only 45 percent of wheat acreage is irrigated.

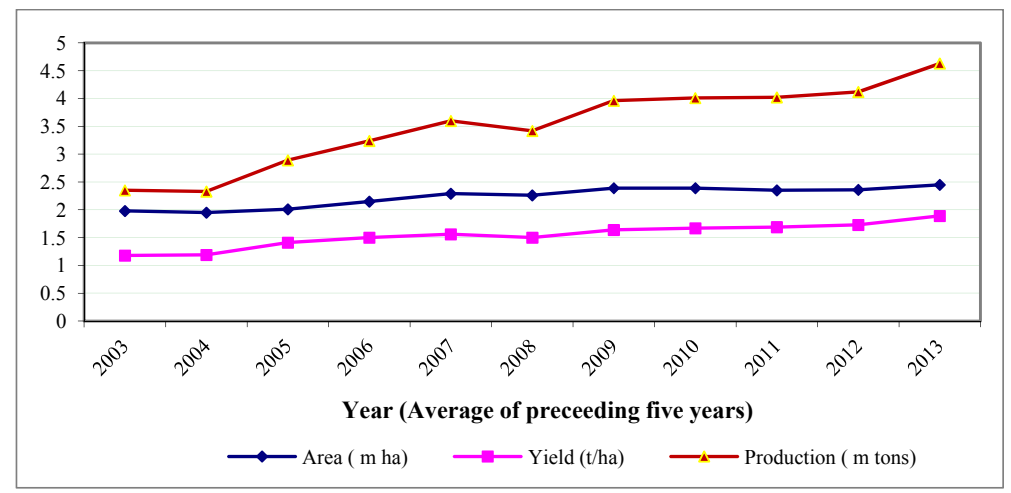

Figure 1. Five year rolling averages

However, rainfed wheat accounts for about 55\% of wheat acreage in Afghanistan. It added substantially to the country's wheat harvest during such plentiful rainfall years as 2009 and 2012. Being opportunistic, rainfed cannot be a reliable contributor to Afghan wheat production, but needs to be supported with all available technology and policy support so as to become a more consistent contributor to wheat coffers of Afghanistan. 


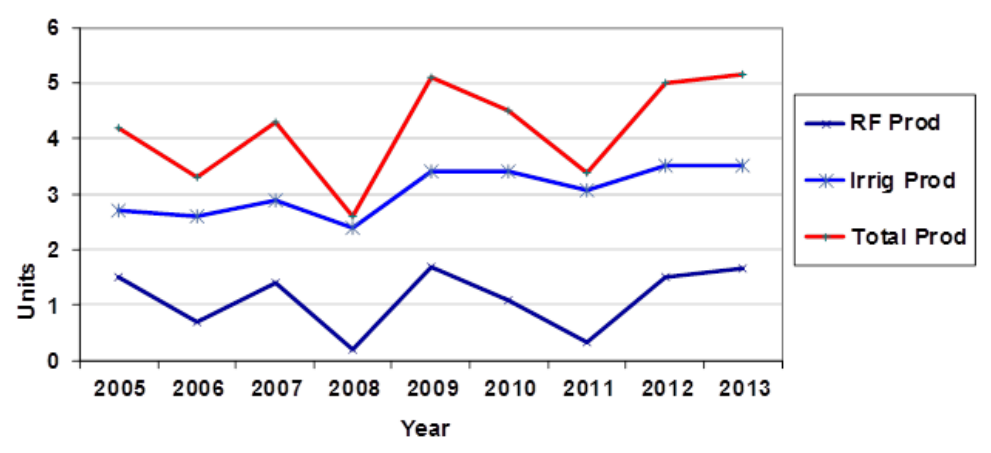

Figure 2. Rainfed \& irrigated wheat production (m tons) \& productivity (t/ha) trends from 2005 to 2012

Over the past ten years, rainfed wheat has contributed from a low of 7.7\% (2008) to a high of about $35.7 \%$ (2005) of total wheat production in the country (FAO, 2014). This equals to an average contribution of $26 \%$ during past ten years. The contribution by rainfed wheat, thus, has been very erratic (Figure 2) and off course unpredictable with a coefficient of variation of about $53 \%$. The average contribution of $26 \%$ looks impressive, however, a share of this or higher magnitude has come only in five out of ten years. Therefore, for assigning a credible role to rainfed wheat in food security assessment of Afghanistan, 15\% contribution looks more realistic as rainfed wheat has contributed $15 \%$ or more than $15 \%$ of wheat production in eight of last ten years (FAO, 2013; MAIL, 2012). Ministry of Agriculture, Irrigation \& Livestock (MAIL) of Afghanistan has estimated that country would need about seven million metric tons of wheat by 2022 to achieve self-sufficiency (Waziri et al., 2013). At a 15 per cent share, rainfed wheat could therefore potentially contribute 1.05 million metric ton and the irrigated wheat would have to contribute 5.95 million metric tons in 2022 to achieve self-sufficiency target.

The most viable option to increase wheat productivity in Afghanistan is to bring more farmland under irrigation using the best available options. Afghanistan brought 28,000 hectares of land under irrigation in the year 2011 (APR, 2012). At this rate, country can increase irrigated wheat acreage by about 7 percent every three years. Concerted efforts need to be made to bring more area under irrigation. Proven available technologies like sprinkler irrigation should be promoted to provide supplementary irrigation wherever possible.

\section{Afghanistan Climate}

Although Afghanistan is a landlocked mountainous country geographically located in central Asia, it is a member of the South Asian Association for Regional Cooperation (SAARC). The country has three distinct geographical regions divided by the Hindu Kush mountains that run on a diagonal from the northeast to the southwest forming central highlands that make up about two thirds of the country's terrain. The northern plains bordering Turkmenistan and southwestern plateau bordering Iran are the other two major geographical regions of the country.

Afghanistan's climate can be typically characterized as semi-arid or arid steppe with cold winters and dry summer. The mountainous northeastern region is subarctic climate and experiences cold winters. The country receives most of its precipitation mainly in winter - at higher altitudes it falls as snow. Some eastern areas bordering Pakistan benefit from southeastern monsoon rains. However, the heavy rains do not extend to the southwest, and mountains on the Pakistan side shelter the Northeast. Temperature regimes are greatly modified by altitude. Lower elevations remain almost frost-free with very hot summers, whereas higher areas experience arctic temperatures in winter. The minimum temperature can drop lower than minus 20 degrees Celsius (minus 4 degrees Fahrenheit) in the central highlands while the maximum can be as high as 30 degrees Celsius in the same region during the summer. The maximum temperature can rise to above 40 degrees Celsius in the east and Southwest during the summer months.

\section{Climate Trends}

Wheat is a cool season crop and Afghanistan's climate offers ample scope for its successful cultivation. Wheat crops can be found in fields year round in different parts of the country. Winter wheat sowings can start in October in the central highlands whereas a spring sown wheat can be harvested after August in the same region. Temperature regimes and precipitation from October to June affect wheat crops in Afghanistan. Depending on how low winter temperatures tread, crop would grow slow or would be under snow for different periods. Similarly, rainfall distribution can also cause million ton variations (Sharma \& Habibi, 2012) in country's wheat 
harvest. A study of average monthly rainfall and minimum and maximum temperatures from 1951 to 2009 (CCAFS, 2014) reveals (Figure 3) that the average monthly rainfall between October and June has reduced by up to 15 millimeters ( 0.039 inches) per month in the eastern Nangarhar province compared to just 1 millimeter per month in the southern provinces of Kandhar and Helmund. The average reduction in precipitation during these nine months has been about 100 millimeters for eastern Paktiya and Kabul provinces. Increase in mean minimum and mean maximum temperature has been about 2 degrees Celsius for Badakhshan, Ghor, Helmund, Herat and Kandahar provinces. Temperatures have remained relatively unaffected in Kabul and Paktya.

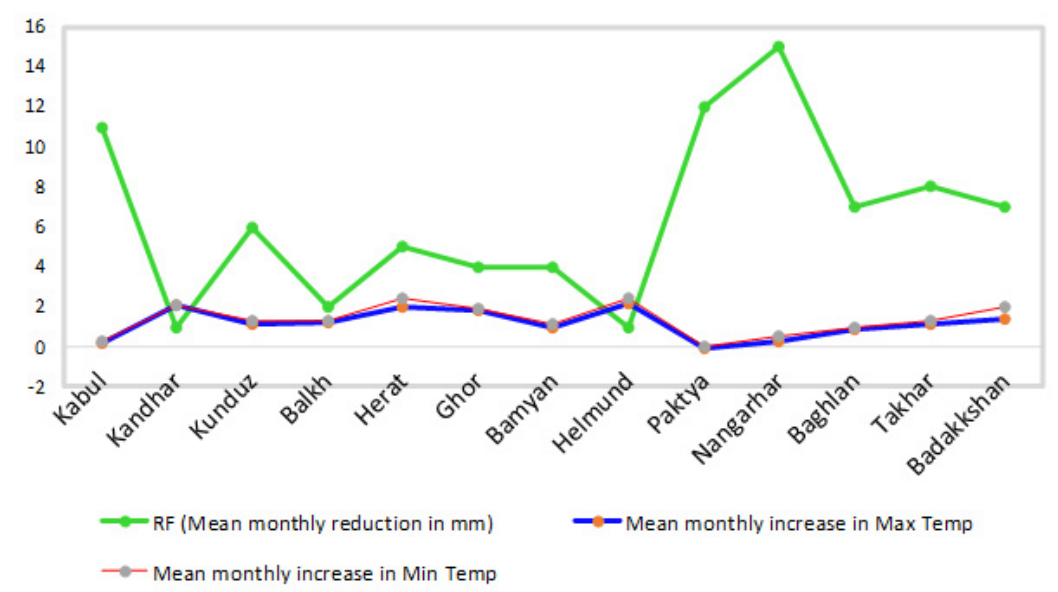

Figure 3. Change in rainfall (RF) and temperature $\left({ }^{\circ} \mathrm{C}\right)$ averages of 2001-2009 compared to 1951-1960 averages at different research stations of Afghanistan

A perusal of wheat phenology reveals that precipitation between March and May is most crucial as grain development and filling takes place during this period. Figure 2 shows drastic dips in wheat production in the country owing mainly to poor precipitation. This is to be noted that although 45 percent of wheat acreage is irrigated, all wheat growing throughout the country benefits from rainfall during these three months.

Figure 4 shows the important relationship between the country's wheat production and the average monthly rainfall between October and June from 2002 to 2009, indicated by a very strong correlation of 0.89 proving the important role played by precipitation during these months. Similarly, national production figures for rainfed wheat are also strongly correlated with rainfall during three months as indicated by correlation coefficient of 0.89 (Figure 5). This finding shows that although the precipitation during the entire crop growth from October to June is important, the amount received in the early growth phase enable crop establishment and the formation of a larger yield potential, but the rains received during March to May allow the realization of established potential.

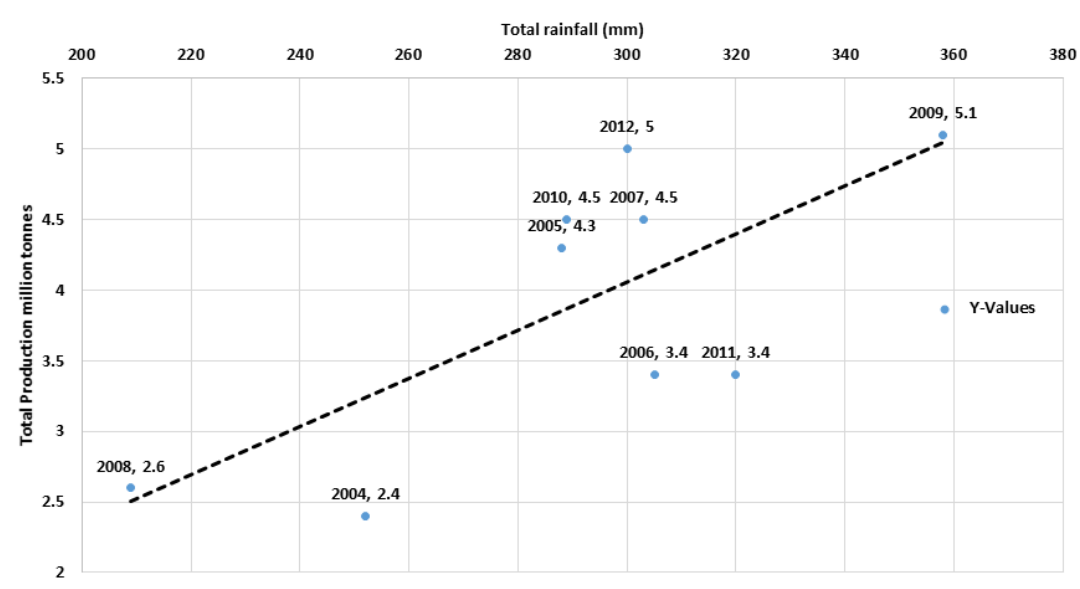

Figure 4. How does total rainfall relate to total production 


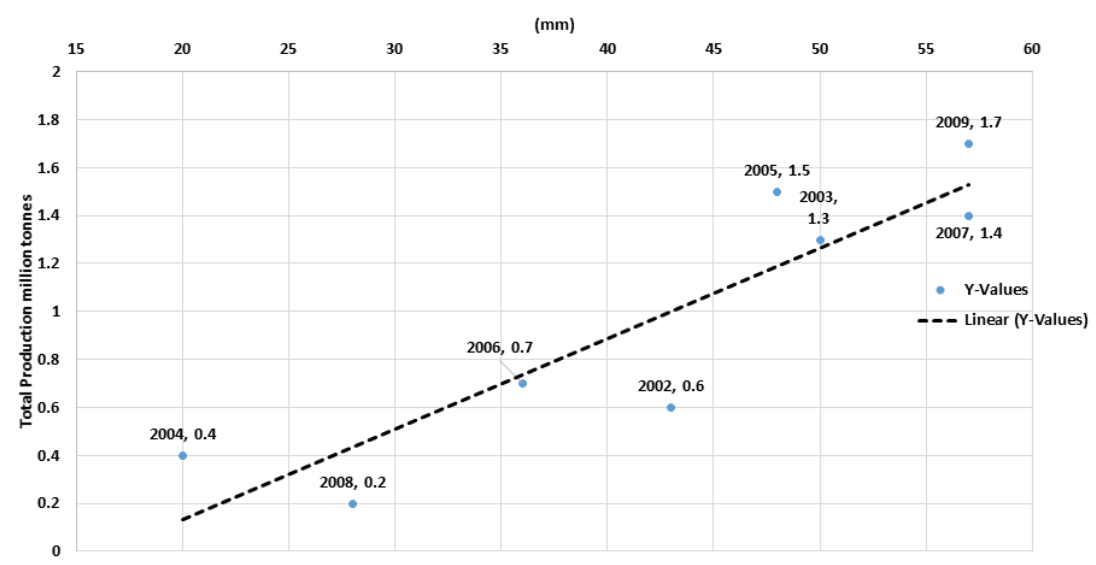

Figure 5. How does March to May rainfall relate to rainfed production

\section{Potential Impact of Climate Change on Wheat}

The world is experiencing climate change characterized in part by reduced precipitation and warmer temperatures (IPCC, 2014), the two parameters that greatly influence crop growth. Indeed, findings by the IPCC support claims that crop yields have been hit by negative impacts of climate change, expressing high confidence that it is not yet clear whether the balance of impacts has been negative or positive in high-latitude regions. In a recent report, the IPCC expresses medium confidence that climate change has negatively affected wheat and maize yields in many regions and in the global aggregate.

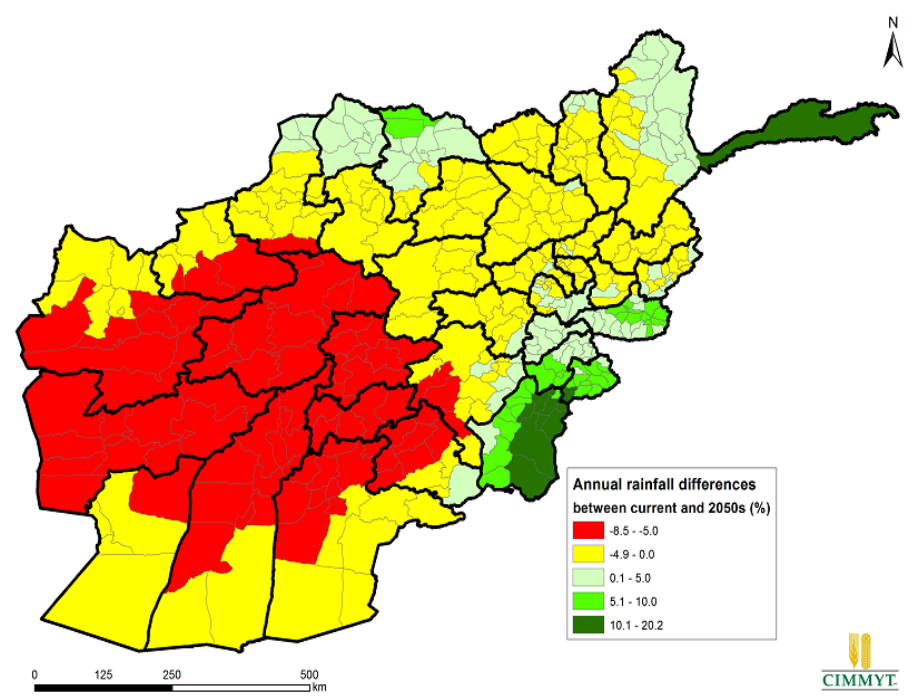

Figure 6. Projected \% changes in rainfall in Afghanistan from now and 2050

Over the past 60 years, data from 13 research sites, on many of which CIMMYT currently conducts its trials, reveal reduced rainfall whereas temperatures have increased. Based on these data, Figures 6 to 8 present projected changes in annual mean rainfall, annual mean maximum temperature and annual mean minimum temperatures in Afghanistan from now until 2050 (CCAFS, 2014). Predictions indicate a potential reduction of average mean rainfall in some parts of Afghanistan by up to 8.5 percent, whereas about 20 percent of the country will in fact see an increase in annual mean precipitation by up to 20 percent, thereby benefiting wheat crop in some regions. Similarly, both mean minimum and mean maximum temperatures are expected to increase by up to 4.5 and 5 degrees Celsius, respectively. 


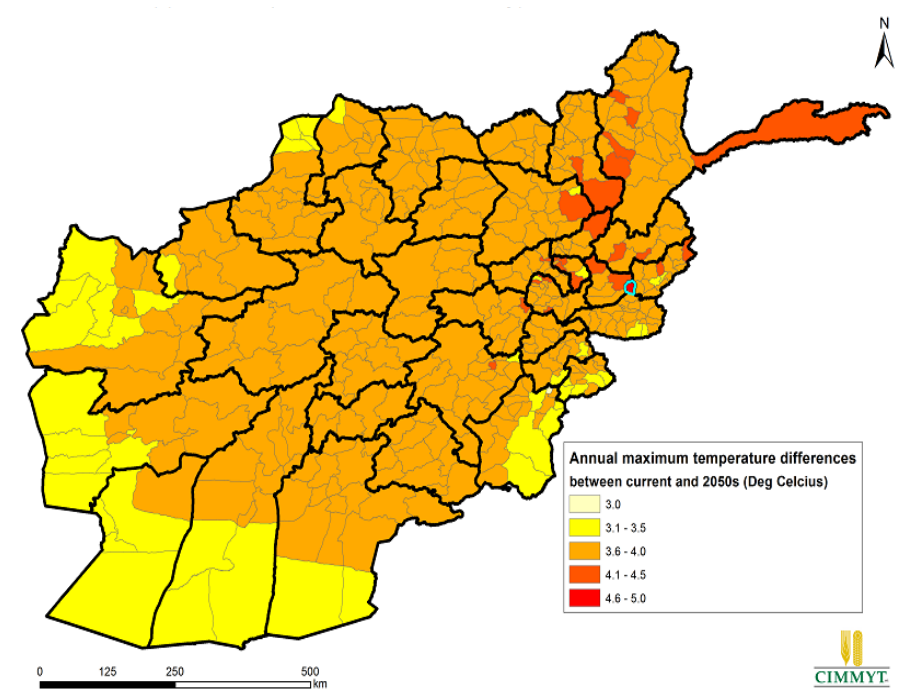

Figure 7. Projected change in annual mean maximum temperature in Afghanistan from now and 2050

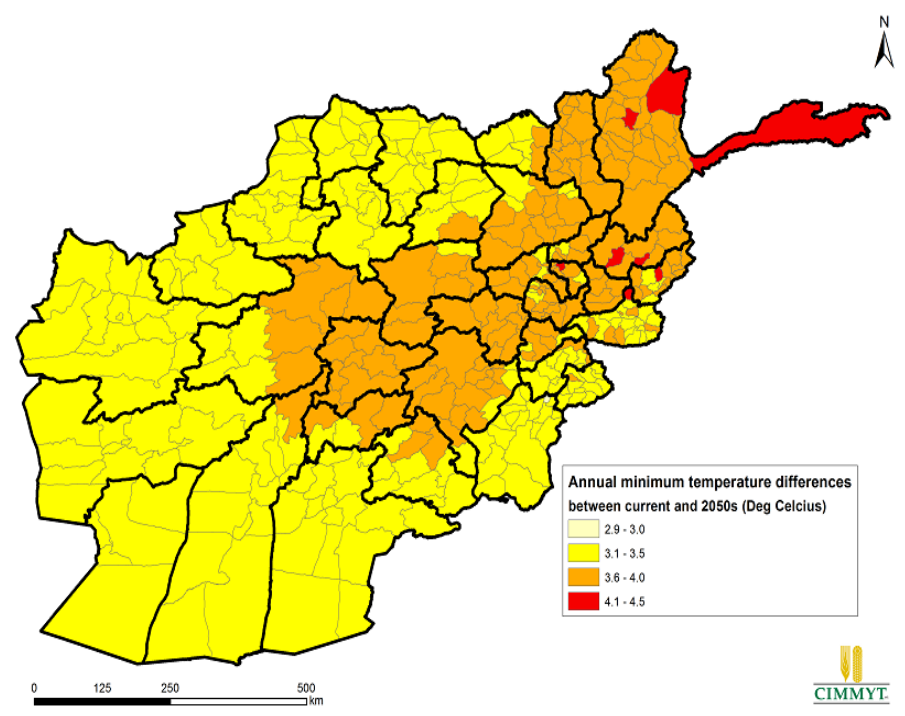

Figure 8. Annual mean minimum temperature projections in Afghanistan from now to 2050

\section{Conclusion \& Recommendations}

Afghanistan has a diverse topography, and cultivates both rainfed and irrigated wheat. These two production domains respond differently to climate change and can thus be impacted differentially. Findings indicate that people in general assume that climate change always leads to a negative impact on crop plants, but that is not the case always. For example, warmer mean temperatures have resulted in considerable yield increases in highland maize when there is a sufficient supply of water. 


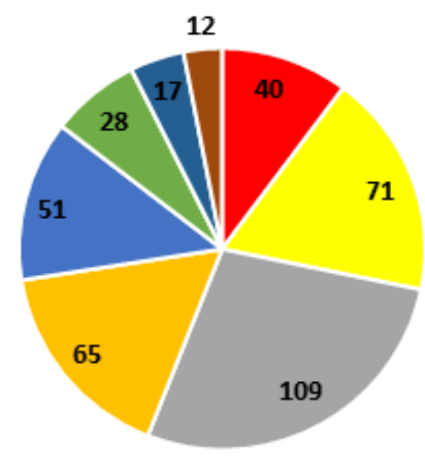

- -50 to $-100=-1$ to $-50=0$ to $50=51$ to $100=101$ to $150=151$ to $200=201$ to $250=251$ to $>400$

Figure 9. No. of districts (Figure in Pie dia) suffering \% change in yield of rainfed wheat in Afghanistan by the year 2050

In Afghanistan, rainfed wheat in areas subjected to warmer mean temperatures and a decline in precipitation, crops might experience severe negative consequences. On the contrary, in cooler areas with enough water when temperatures become warmer yields may not decline or even go up. Assuming sufficient availability of irrigation, higher temperatures are often compensated and could even accelerate growth to higher yields.

On the other hand, the IPCC reports with high confidence that glaciers are shrinking almost worldwide due to climate change and has medium confidence that the phenomenon is affecting runoff and water resources downstream. The IPCC reports with high confidence that climate change is causing permafrost warming and thawing in high-latitude regions and in high-elevation regions. Melting glaciers may lead to problems with the volume of irrigation water feeding crops. However, the general assumption is that at least temporarily river flow will increase due to the thawing leading to greater availability of water. The climate change assessments for 2050 (CCAFS, 2014) indicate that rainfed wheat yields in Afghanistan would decline only in 114 districts to the tune of up to 100 percent, whereas climate change is expected to increase rainfed wheat yields in about 280 districts by up to 400 percent (Figure 9).

Wheat being a $\mathrm{C} 3$ crop will be able to use higher future $\mathrm{CO}_{2}$ concentrations to increase photosynthesis. As a result, in many cases many of the negative effects of climate change may be balanced out. Ultimately, yields may even increase beyond current levels if general suitability doesn't decline. Some researchers discuss this effect but from what is available in literature, it is logical to include this. An analysis CIMMYT undertook on wheat and climate change in Ethiopia showed little decline of yield or increase of yield for the 2050s partly due to the $\mathrm{CO}_{2}$ effect and the combination of higher temperatures with constant or increases in rainfall.

\section{Acknowledgements}

This work was supported in part by funds provided through a grant from the Australian Centre for International Agricultural Research (ACIAR) to CIMMYT. We acknowledge the help of Julie Mollins, CIMMYT-Mexico for editing the article.

\section{References}

CCAFS. (2014). Retrieved from http://www.ccafs-climate.org

FAO. (2013). Retrieved from http:/faostat.fao.org

IPC. (2013). Integrated food security phase classification. Retrieved from http://www.ipcinfo.org

IPCC. (2014). Retrieved from http://ipcc-wg2.gov/AR5/images/uploads/WG2AR5_SPM_FINAL.pdf

IPCC. (2014). Summary for policymakers. In C. B. Field, V. R. Barros, D. J. Dokken, K. J. Mach, M. D. Mastrandrea,T. E. Bilir, ... L. L. White (Eds.), Climate Change 2014: Impacts,Adaptation, and Vulnerability. Part A: Global and Sectoral Aspects. Contribution of Working Group II to the Fifth Assessment Report of the Intergovernmental Panel on Climate Change (pp. 1-32). Cambridge, United Kingdom and New York, NY, USA, Cambridge University Press.

MAIL. (2009). Agricultural Prospects Report. Ministry of Agriculture, Irrigation \& Livestock, Kabul, Government of Afghanistan. 
MAIL. (2012). Agricultural Prospects Report. Ministry of Agriculture, Irrigation \& Livestock, Kabul, Government of Afghanistan.

Persaud, S. (2012). Long-Term Growth Prospects for Wheat Production in Afghanistan. Retrieved from http://www.ers.usda.gov/media/193523/whs11101_1_.pdf

Sharma, R., \& Habibi, H. K. (2012). Wheat secure Afghanistan: assessing priorities. eWIS, 115, 11-15.

Waziri, A., Habibi, A., Manan, A. R., Rabbani, H., Kamalzai, H., Alawi, K. S., ... Sharma, R. (2013). Making Afghanistan wheat secure by 2022. eWIS, 116, 12-14.

WFP. (2014). Retrieved from https://www.wfp.org/countries/afghanistan/overview

World Bank. (2013). Retrieved from http://data.worldbank.org/country/afghanistan

\section{Copyrights}

Copyright for this article is retained by the author(s), with first publication rights granted to the journal.

This is an open-access article distributed under the terms and conditions of the Creative Commons Attribution license (http://creativecommons.org/licenses/by/3.0/). 